\title{
Structural equation modeling in the acceptance of internet banking in the city of Split
}

\author{
Marija Vukovići ${ }^{1, *}$, Snježana Pivac ${ }^{1}$, Duje Kundid ${ }^{2}$ \\ ${ }^{1}$ Faculty of Economics, Business and Tourism, University of Split \\ Cvite Fiskovića 5, 21000 Split, Croatia \\ E-mail: $\langle\{$ mvukovic, spivac\}@efst.hr $\rangle$ \\ ${ }^{2}$ SeekandHit in Split, Stinice 12/II, 21000 Split, Croatia \\ E-mail:〈duje.kundid@gmail.com〉
}

\begin{abstract}
Electronic banking and electronic commerce have lately become an inevitable aspect of financial services. According to data about the percentage of users of Internet banking in Europe, Croatia is at the bottom of the list, with a low number of users. Thus, the question of the acceptance and use of this kind of technology arises. This research uses structural equation modeling to explore whether the motivation for the acceptance and use of Internet banking can be explained by the technology acceptance model (TAM) in the city of Split, Croatia. TAM explains the intent of using information systems through the perceived ease of use and the perceived usefulness of a system. It consists of multiple causal relationships, so structural equation modeling is adequate for hypothesis testing. A survey analysis was designed and applied on a sample of 282 working residents of Split. To make the results more credible, the gender and age structure of the sample was harmonized with the population. It is concluded that both elements of TAM positively influence the acceptance of Internet banking in Split. Since there is not much research on the use of Internet banking in Croatia and Southeast Europe, this research contributes to the poor amount of literature in this scientific area for these countries. The research findings can also help banks to understand the factors of Internet banking acceptance and to develop expansion strategies. Future research could include a cross-country comparison of individuals' perception about Internet banking, as well as the dependence relationships of TAM factors.
\end{abstract}

Keywords: internet banking, structural equation modeling, survey analysis, technology acceptance model

Received: November 2, 2018; accepted: April 5, 2019; available online: July 4, 2019

DOI: $10.17535 /$ crorr.2019.0013

\section{Introduction}

Internet banking has lately become one of the most important banking services. It has undergone numerous technological improvements in order to increase the number of its users. It is a banking practice which allows customers to access their bank accounts and perform financial transactions online. Thus, Internet banking enables customers to perform such transactions as transfers and payments, access of balance, viewing of accounts statements and details, customization printing, printing out bank statements, etc. [15]. In order to explain the factors which influence the acceptance and use of Internet banking among the population, many authors have used the technology acceptance model (TAM), one of the most utilized models in studying information system acceptance $[1,5,7,8,10,18,20,22,24,26,27,30,36]$. This model consists of multiple causal relationships. Firstly, system use (actual behavior) is determined

${ }^{*}$ Corresponding author. 
by perceived usefulness and perceived ease of use. These elements then relate to the attitude toward use, which relates to intention and finally to behavior [24]. Therefore, if the customer thinks that using Internet banking is simple and useful, it should have a positive impact on his/her intention of actual Internet banking use. It is expected that the acceptance and use of this service can be explained by TAM through its main elements.

The research hypothesis states that the perception of individuals affects the acceptance and use of Internet banking in the city of Split, Croatia. Split is the second largest city in Croatia [6], so it is assumed that the research results could reflect the actual perception of individuals across the whole country. The research is based on a survey analysis which was designed according to previous research $[4,24,34,37]$, and applied to a sample of 282 working residents of Split. In order to make the results more credible, the gender and age structure of the sample was harmonized with the population. Descriptive statistics was used to describe the sample, and structural equation modeling was used to test the hypothesis. Most of the previous research about Internet banking adoption was made in Asian, American and European countries which all have high numbers of Internet banking users.

This research contributes to the field through new findings on the use of Internet banking in Croatia, since previous research was not focused on Southeast European countries [12]. This contribution can be made if the perception of individuals about Internet banking in Split is the same as in other countries, despite its lower number of Internet banking users. It can also be found if there are differences in the impact of the perceived ease of use and the perceived usefulness of Internet banking between the area of Split and countries with a higher number of Internet banking users. These results can also help bank managers to understand the factors of Internet banking acceptance and to develop an expansion strategy, especially in countries with a lower number of users, including Croatia. Banks should also do more advertising to attract more Internet banking users as well as consider educational programs in order to encourage older residents to start using Internet banking. Additionally, they should consider offering more favorable conditions for their clients who already use this service.

After this introduction, the theoretical framework and literature review is provided. The next section refers to the research methodology as well as the research instrument and sample description. Then, the results of the empirical analysis are presented and discussed. Finally, a conclusion and recommendation for future research is stated.

\section{Theoretical framework and literature review}

In today's dynamic environment, the Internet has become the most important tool for business, including banking, since the clients of banks use online services more often. It is particularly noticeable through the increased usage of Internet banking service. Internet banking can be defined as the distribution of banking products and services using the Internet [3] or a banking practice which allows customers to access their bank accounts online [15]. According to [13] electronic banking and electronic commerce have lately become an inevitable aspect of financial services. Electronic banking can be explained as providing bank products and services through electronic delivery channels, whereas Internet banking is a type of electronic banking [21].

User acceptance of information technologies and information systems presents an important field of study. Researchers have used several theoretical models in order to determine the factors of the acceptance and use of a new system, but the technology acceptance model (TAM), proposed by Fred Davis [7], has captured the most attention [5]. According to TAM, system use can be explained by user motivation, which is directly influenced by the actual system's features and capabilities. It is stated that two psychological elements, perceived ease of use (PEOU) and perceived usefulness (PU), along with the attitude toward using the system, can explain the user's motivation for using an information system. TAM later evolved and the development of the model included behavioral intention as a new variable directly influenced 
by PU and PEOU [8]. Both of these original TAM elements were also found to have a direct influence on behavioral intention (BI), so the final version of TAM featured only one change when compared to the original version: the replacement of the attitude toward using construct with the behavioral intention construct. The external variables influencing PU and PEOU can include system characteristics, socio-demographic characteristics, marketing efforts, training, user involvement in design, etc. [35]. The comparison of the original and final versions of TAM can be seen in Figure 1.

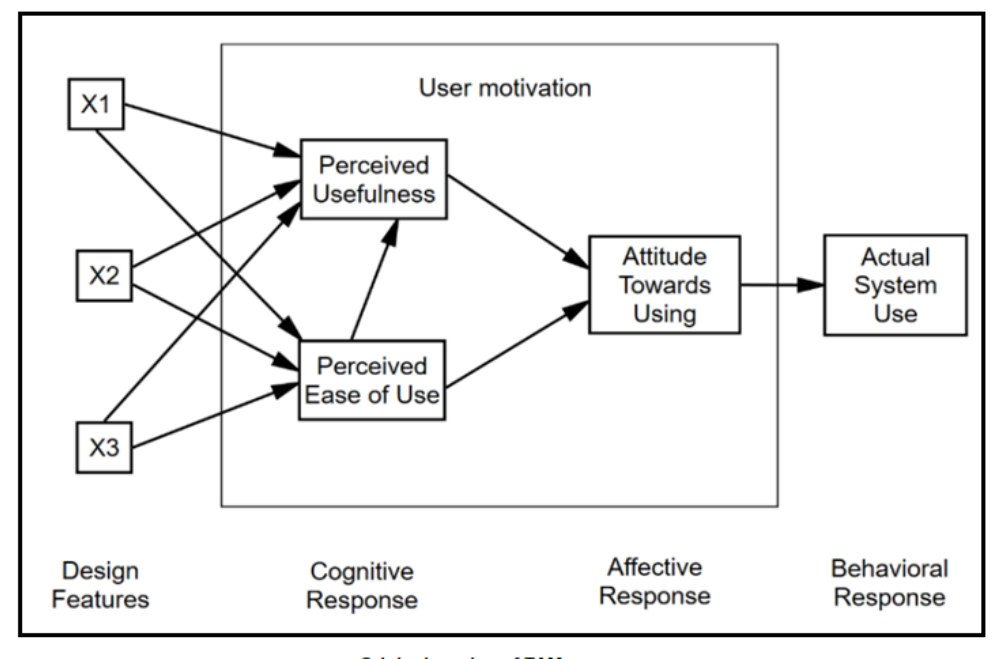

Original version of TAM

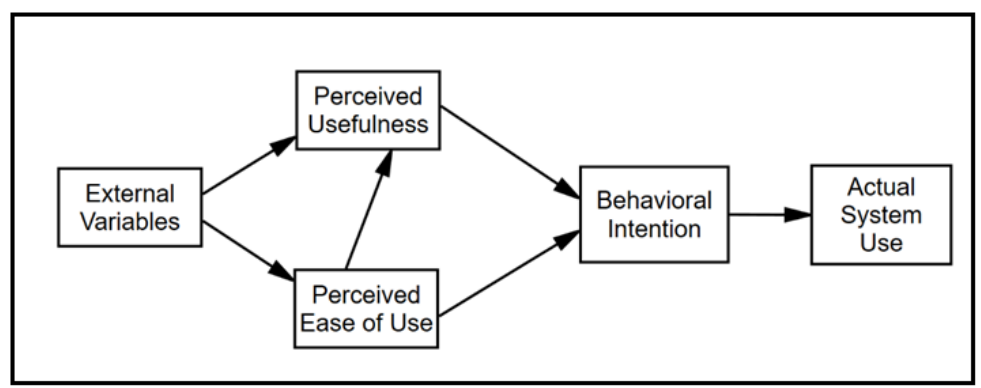

Final version of TAM

Figure 1: Comparison of the original and final versions of TAM

Although TAM consists of two main elements (PEOU and PU), many authors have expanded and tested the model with additional variables. In most research it was found that PEOU significantly affects the acceptance and use of Internet banking (IB). Sharma and Govindaluri [30] investigated the adoption of Internet technologies by banking users through an extended TAM model among 344 current or potential IB users in India. Through structural equation modeling (SEM), they found that PU and PEOU, among other variables, determine the attitude toward IB usage, which can predict the intention to use an IB service. Another research regarding the impact of PE and PEOU on IB adoption was conducted among 517 bank customers in Jordan by SEM. As hypothesized, both of these factors were found to have a significant positive effect on IB adoption, with PU having a higher impact [1]. Research on IB adoption using Grounded Theory Literature Review and two-stage random-effects meta-analytic structural equation modeling (MASEM) methods also found that PU and PEOU positively influence 
IB adoption, where PU was also a stronger predictor. In addition, it was found that PEOU has a positive significant impact on PU [20]. These conclusions were previously supported by other authors as well [22, 28, 36]. Tarhini et al. [31] also used SEM to explore IB adoption in Lebanon. Among several different variables, their proposed theoretical model included performance expectancy (PE) and effort expectancy (EE). According to their definitions, $\mathrm{PE}$ is equivalent to $\mathrm{PU}$ in TAM, and $\mathrm{EE}$ is equivalent to PEOU. It was concluded that $\mathrm{PE}$ was the strongest determinant of IB adoption within the proposed model, while EE did not have a significant impact. This finding is inconsistent with previous research, but it can be explained by the fact that difficulty in using the Internet and computers is becoming less of a concern for consumers as user friendliness increases. Similarly, in research conducted in Vietnam [4], it was found through correlation and multiple regression analysis that PEOU does not affect the use of IB, which is not in accordance with theoretical expectations.

This unexpected result is explained by the fact that most of the respondents in the study are relatively young (age 21-30), so they believe that they can learn IB easily, thus ease of use does not represent a barrier to their adoption of IB. Other studies also included additional influential factors on IB adoption. Safeena et al. [27] confirmed the positive influence of PU and PEOU on IB adoption and found that PU is a stronger predictor. By using hierarchical regression analysis, they also found the influence of perceived benefit, perceived impediment, social influence and demographic factors on IB adoption in India. In research in the United Kingdom [38], cluster and confirmatory factor analysis was used to conclude that technology readiness, age and gender moderate the beliefs-intention relationship. Research by Sadeghi and Farokhian [26] also combined several models and theories, including TAM, to explore IB adoption in Iran through SEM. They proposed a model with seven factors, among which some factors showed a significant statistical difference between males and females, but there was no difference in general satisfaction with electronic banking between them. According to Eurostat data [9], there is a growing trend of IB users. In most European countries, the percentage of users in 2017 was above $50 \%$. Scandinavian and Benelux countries had more than $70 \%$, and some even more than $90 \%$ of IB users in 2017. On the other hand, most Southeast European countries, including Croatia, are at the bottom of the list, with Bulgaria and Montenegro having only $5 \%$ and $4 \%$ of users in 2017. Croatia had $33 \%$ of users in 2017 , which is 5 percentage points less than the previous year. There is not much research regarding IB adoption in this geographical area. Most of the research was done in Asian and North American countries, while the research in European countries mostly focused on countries with higher numbers of IB users [12]. Some research on IB adoption in countries with lower numbers of users include a segmentation study on a sample of Greek customers by using cluster analysis. Three segments were identified, and different characteristics between adopters and non-adopters were found, while only income was found to be associated with segment membership [23]. Gounaris and Koritos [10] also did research in Greece through confirmatory factor analysis and logistic regression, and they concluded that relative advantage and ease of use, demographics as well as psychographics influence IB adoption. Research in Poland [25] using logistic regression showed that the behavior of Polish Internet users has similar traits to that of consumers in more developed countries. It was found that IB adoption was influenced by perceived level of security, demographic variables and advertising. Makarević [19] analyzed and compared the perceptions of clients from Bosnia and Herzegovina with those of Croatia regarding information technology security in IB banking by using descriptive statistics. The results indicate that "Croatian clients think that banks are able to protect their privacy completely and that banks are doing their best to improve the confidentiality of online transactions. On the other hand, clients from Bosnia and Herzegovina agree and trust banks when it comes to aspects of control, but people still feel somewhat unsafe, which could be the reason why there is no significant increase in the trend line of electronic banking development in Bosnia and Herzegovina". Liébana-Cabanillas et al. [18] studied the key factors that influence consumers' adoption of mobile commerce in the Republic 
of Serbia through a SEM-neural network approach. They developed a model with six potential predictors of behavioral intention, including usefulness and ease of use, but customization and customer involvement turned out to be the strongest predictors of behavioral intention.

To summarize, most of the previous research used PEOU and PU as predictors of IB adoption in their models, either through studying TAM and expanded TAM versions or by including these variables in other theories and models. Their results have generally shown the positive influence of both factors on IB adoption, with PU as a stronger predictor [1, 20, 22, 28, 30, 36]. However, [4] and [31] found that PEOU does not affect the use of IB. Not many studies have been conducted on IB adoption in Croatia and countries with lower number of users in general. Therefore, this research aims to determine whether the motivation for using IB in the city of Split, Croatia, can be explained by the PEOU and PU of IB. The results can provide the answer to the question of whether IB adoption in Split, the second largest city in Croatia, is under the same influential factors as other countries, despite its lower number of IB users.

Considering the aim of this research, the main research hypothesis, along with two auxiliary hypotheses, is proposed:

$H_{1}$ : The perception of individuals affects the acceptance and use of Internet banking in the city of Split, Croatia

$H_{1 a}$ : The perceived ease of use of Internet banking has a positive effect on the acceptance of Internet banking

$H_{1 b}$ : The perceived usefulness of Internet banking has a positive effect on the acceptance of Internet banking

\section{Methodology}

\subsection{Research instrument}

In order to conduct the research, a survey analysis, designed according to previous research, was applied. The research was carried out in the period of April to July 2017. An electronic version of the survey was distributed via social networks and e-mail, while a printed version was directly distributed to people who do not use the Internet [17]. The survey consists of 16 questions divided into several groups. Some questions refer to the PEOU and PU of IB, while others refer to the individual characteristics of respondents. The questions relating to the intention of continuing or starting to use IB represent the behavioral intention of respondents.

As mentioned above, the survey was based on previous research. The questions on the frequency and length of IB usage and the frequency of using certain IB functionalities were formulated according to [34]. The questions on PEOU and PU were formulated according to [24] and [37]. while the question on the intention of IB adoption was formulated according to [4]. The answers to the survey questions regarding agreement with certain statements measuring PEOU and PU were formulated as a $1-5$ Likert scale ( $1=$ strongly disagree, $5=$ strongly agree), as is usual in all levels of the Croatian education system ( $1=$ negative grade, $5=$ excellent grade) and for social research.

\subsection{Data}

The research focuses on the working population in Split. The working population is the total population in a region, aged 15 to 64 , that is considered to be able and likely to work. According to the latest census in 2011, the total working population of Split was 121,242 residents [6] A sample size of 383 was determined according to a 0.95 confidence interval and 0.05 margin of error. However, since not all the surveys were filled out, the final sample includes 282 working residents of Split, which corresponds to a sample size with a 0.90 confidence level and 0.05 margin of error. 
The gender and age structure of the sample was harmonized with the population to make the results more credible. $51.42 \%$ of female respondents and $48.58 \%$ of male respondents were equally distributed in each of the five different age groups ( $\leq 24$ years, $25-34$ years, $35-44$ years, 45-54 years and 55-64 years). Table 1 shows the sample structure by gender and age.

\begin{tabular}{|c|ccc|cc|}
\hline Age & \multicolumn{2}{|c|}{ Female } & Male & \multicolumn{2}{|c|}{ Total } \\
\hline$\leq 24$ years & $28(9.9 \%)$ & $24(8.5 \%)$ & $52(18.4 \%)$ \\
$25-34$ years & $27(9.6 \%)$ & $31(11.0 \%)$ & $58(20.6 \%)$ \\
35 - 44 years & $30(10.6 \%)$ & $26(9.2 \%)$ & $56(19.9 \%)$ \\
45 - 54 years & $30(10.6 \%)$ & $28(9.9 \%)$ & $58(20.6 \%)$ \\
55 - 64 years & $30(10.6 \%)$ & $28(9.9 \%)$ & $58(20.6 \%)$ \\
\hline Total & $145(51.4 \%)$ & 137 & $(48.6 \%)$ & $282(100.0 \%)$ \\
\hline
\end{tabular}

Table 1: Sample structure by gender and age (column percentages in the brackets)

Therefore, the sample can be considered a combination of stratified and quota samples, since the population was first divided into separate strata and then a random sample from each stratum was taken in a number proportional to the stratum's size when compared to the population [33].

\subsection{Statistics}

The SPSS 23.0 and Mplus 7.0 statistical packages were used to analyze the data collected from the survey. Validity was tested through the average variance extracted to measure convergence among a set of items representing a latent construct. In addition, a reliability analysis was conducted using Cronbach's alpha coefficients to determine the extent to which the variables are consistent in their values [11]. Finally, structural equation modeling (SEM) was used to test the research hypothesis. It is an adequate method since the technology acceptance model consists of multiple causal relationships.

"Structural equation modeling is a multivariate technique which combines aspects of factor analysis and multiple regression. It enables the simultaneous examination of a series of interrelated dependence relationships between the measured variables and latent constructs, as well as between several latent constructs" [11]. Latent constructs represent the operationalization of a construct in SEM, which is not directly observable, but can be measured by one or more variables (indicators). These indicators are called measured (observed, manifest) variables, for which scores are collected and entered in a data file $[11,16]$. The first step in a structural model analysis is to develop a measurement model which specifies the indicators for each construct and enables an assessment of construct validity. It shows how the measured variables come together to represent latent constructs. When the measurement model shows good fit, a structural model is specified. This model represents a set of one or more dependence relationships between the latent constructs [11]. The latent constructs which were used in the model are those according to the proposed technology acceptance model. They are measured through several variables, which are represented by the corresponding questions from the survey.

Although SEM is considered a powerful technique, it has its flaws. Firstly, SEM analysis should have a strong theoretical base, but sometimes researchers do not provide a sufficient theoretical justification for their model. Instead, they can just look for statistically significant results [29].

As mentioned, since TAM consists of multiple causal relationships, SEM is an appropriate method of analysis. The model for acceptance of IB in this research is based on the final version of TAM, shown in Figure 2. However, it was focused only on the impact of the perception of individuals on the behavioral intention of IB usage. 
A path diagram for the theoretical model is shown in Figure 2 and it is followed by a set of equations which describe the relationships of the model:

$$
\begin{array}{r}
P E O U_{1}=\beta_{1} P E O U+e_{1} \\
P E O U_{2}=\beta_{2} P E O U+e_{2} \\
P E O U_{3}=\beta_{3} P E O U+e_{3} \\
P E O U_{4}=\beta_{4} P E O U+e_{4} \\
P U_{1}=\beta_{5} P U+e_{5} \\
P U_{2}=\beta_{6} P U+e_{6} \\
P U_{3}=\beta_{7} P U+e_{7} \\
P U_{4}=\beta_{8} P U+e_{8} \\
P U_{5}=\beta_{9} P U+e_{9} \\
B I_{1}=\beta_{10} P U+e_{10} \\
B I_{2}=\beta_{11} P U+e_{11} \\
P U=\beta_{12} P E O U+e_{12} \\
B I=\beta_{13} P E O U+\beta 14 P U+e_{13}
\end{array}
$$

where the appropriate items represent: PEOU - Perceived ease of use; PEOU1 - I believe that the use of Internet banking is easy to learn (it would be easy to learn); PEOU2 - I believe that the use of Internet banking is clear and understandable (it would be clear and understandable to me); PEOU3 - I believe that Internet banking is easy to use (it would be easy for me to use); PEOU4 - I believe that it is easy to gain the skills of Internet banking use (it would be easy for me to gain Internet banking skills); PU - Perceived usefulness; PU1 - I consider Internet banking useful; PU2 - I believe that Internet banking eliminates spatial limitations; PU3 - I believe that Internet banking saves time; PU4 - I believe that Internet banking saves money; PU5 - I believe that the use of Internet banking increases productivity; BI - Behavioral intention; BI1 - Do you intend to start/continue to use Internet banking service in the future?; BI2 - Do you intend to frequently use Internet banking service in the future?; $\beta_{1}, \beta_{2}, \ldots, \beta_{14}$ are path coefficients and $e_{1}, e_{2}, \ldots, e_{13}$ error terms.

\section{Empirical results and discussion}

\subsection{Validity and reliability analysis}

In order to test whether the perception of individuals affects the acceptance and use of IB in the city of Split, two auxiliary hypotheses regarding the impact of PEOU and PU on IB adoption were formed, as stated earlier. Since this will be tested by structural equation modeling, it is first necessary to conduct a validity and reliability analysis to measure the convergence among a set of items representing a latent construct and to define the extent to which the variables are consistent in their values [11].

As seen in Table 2, all factor loadings are higher than 0.5 and are statistically significant, thus they show that the indicator variables almost perfectly reflect the latent variable they measure. The average variance extracted (AVE) is a measure of validity, which shows the average percentage of variation explained among the items. All AVE values exceed 0.5, which shows strong validity [11]. Reliability was tested by using Cronbach's alpha coefficients. There are different reports about the acceptable values of alpha, mostly ranging from 0.70 to even 0.95, while some consider the value of 0.60 [31]. Cronbach's alpha coefficients for all the factors are very high, above 0.95 , which shows an internal consistency of the items. 


\begin{tabular}{|l|lc|cc|}
\hline Construct (factor) & Item & Standardized loading & AVE & Cronbach's alpha \\
\hline \multirow{3}{*}{$\begin{array}{l}\text { Perceived ease } \\
\text { of use (PEOU) }\end{array}$} & $\mathrm{PEOU}_{1}$ & $0.994^{* *}$ & & \\
& $\mathrm{PEOU}_{2}$ & $0.987^{* *}$ & 0.974 & 0.985 \\
& $\mathrm{PEOU}_{3}$ & $0.984^{* *}$ & & \\
& $\mathrm{PEOU}_{4}$ & $0.982^{* *}$ & & \\
Perceived & $\mathrm{PU}_{1}$ & $0.961^{* *}$ & & \\
uselfuness (PU) & $\mathrm{PU}_{2}$ & $0.958^{* *}$ & & \\
& $\mathrm{PU}_{3}$ & $0.971^{* *}$ & 0.858 & \\
& $\mathrm{PU}_{4}$ & $0.888^{* *}$ & & \multirow{2}{*}{0.871} \\
\hline \multirow{2}{*}{$\begin{array}{l}\text { Behavioral } \\
\text { intention (BI) }\end{array}$} & $\mathrm{PU}_{5}$ & $0.931^{* *}$ & & \\
\hline
\end{tabular}

Table 2: Validity and reliability of constructs (statistical significance at 5\% and $1 \%$ are denoted by $\left.{ }^{*}, *\right)$

\subsection{Structural equation modeling}

According to the proposed technology acceptance model, the latent constructs of the model are PEOU, PU and BI. Each construct is measured through several variables, represented by the corresponding questions from the survey, which can be seen in table 1. Since the answers to those questions are coded as ordinal variables (1-5 Likert scale), the mean and variance adjusted weighted least squares (WLSMV) method of estimation is used [16]. The hypothesized model consists of three latent constructs and eleven measured variables. The model has 42 degrees of freedom, which makes it overidentified and suitable for analysis. In order to achieve this identification, unit loading identification (ULI) constraints were imposed, i.e. for each of the constructs, one unstandardized coefficient is fixed to equal 1 [17]. Since the BI construct has only two indicators, the solution produced a negative residual variance for variable BI1. For this reason, that estimate was fixed to zero $[11,16]$. Furthermore, the measurement part of the model regarding BI was not identified, so it was necessary also to constrain the BI variance to equal 1.

As it can be seen from Table 2, all model fit statistics show acceptable fit, except for the Chi-square test, which shows a significant result. However, this test statistic can be sensitive to sample size, especially in large samples (over 200), since it increases along with the sample size $[2,11,14,16,29]$. Therefore, considering this limitation of the Chi-square test and the acceptable values of other fit statistics, the model is retained.

Standardized estimates for the model are also shown in Table 3. It can be seen that all estimates are statistically significant at the 0.01 level. The hypothesized relationships of factors in TAM are supported. PEOU has a positive impact on PU, and both of the elements positively affect BI. The highest impact among these latent constructs is the impact of PEOU on PU. However, unlike previous research $[1,20,22,28,36]$, in this model PEOU has a slightly higher impact on BI than does PU. These results indicate that those respondents who have a higher level of agreement with statements that IB is easy to learn, is clear and understandable and that it is easy to use and gain the skills for using it, also intend to start or continue to use IB service in the future. Therefore, hypothesis $H_{1 a}$ is supported. Those respondents with a higher perception of perceived ease of use of IB consequently have a higher perception of IB usefulness. In addition, the respondents who show a higher level of agreement with the statements of IB usefulness, such as eliminating spatial limitations, time and money saving and 
productivity increasing, intend to start or continue to use IB in the future. Thus, hypothesis $H_{1 b}$ is supported.

\begin{tabular}{|l|cc|}
\hline Hypothesized path & Standardized estimates & $p$-value \\
\hline $\mathrm{PEUO} \longrightarrow \mathrm{PU}$ & 0.814 & 0.000 \\
$\mathrm{PEOU} \longrightarrow \mathrm{BI}$ & 0.336 & 0.005 \\
$\mathrm{PU} \longrightarrow \mathrm{BI}$ & 0.318 & 0.006 \\
\hline$\chi^{2}=87.516, p$-value $<0.001$ & RMSEA $(90 \% \mathrm{CI})=0.062(0.04-0.08)$, & $\mathrm{CFI}=0.999$, TLI $=0.999$ \\
\hline
\end{tabular}

Table 3: Results of the structural model with goodness of fit measures

The path diagram of the full model with standardized estimates is shown in figure 2. This model was created according to the final version of TAM, which was previously shown in figure 1. However, in this model, only the perception of individuals, without any particular external variables, was tested. All of the standardized estimates in the model are statistically significant and confirm the proposed causal relationships of TAM.

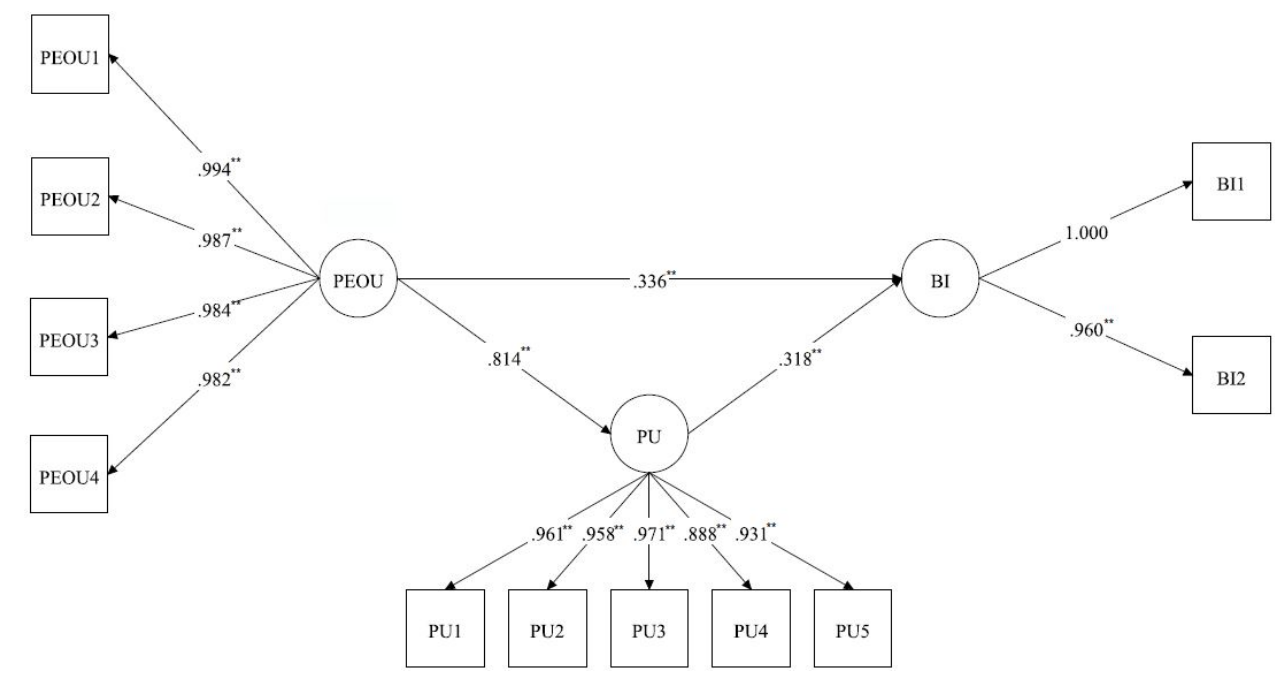

Figure 2: Path diagram with standardized estimates (statistical significance at 5\% and $1 \%$ are denoted by $\left.{ }^{*},{ }^{* *}\right)$

\section{Conclusion}

The aim of this research was to use a structural equation model to explore whether the motivation for the use of IB in the city of Split, Croatia can be explained by PEOU and PU, which are the main elements of TAM. In order to conduct the research, a survey analysis was applied to a sample of 282 working residents of Split, with the gender and age structure of the sample being harmonized with the population to make the results more credible. The results of the structural model indicate that there is a positive influence of PEOU and PU on IB adoption in Split. Specifically, it is found that respondents with a higher level of agreement with the statements of IB ease of use and its usefulness are more likely to adopt IB. This is in accordance with most previous research in other geographical areas. Since there is not much research on IB adoption 
in Croatia, and countries with lower numbers of IB users in general, a research contribution can be recognized in these new findings from these specific economies. It is concluded that, despite the lower number of users, IB adoption in Split, the second largest city in Croatia, is under the same influential factors of TAM with the same direction of influence as in countries with higher numbers of IB users. The designed survey can help future research in this area. The research findings can also help bank managers in other parts of Croatia, as well as in countries with similar economies, to understand the factors of IB acceptance and to develop expansion strategies. This should consequently result in a wider adoption of IB services, which leads to more efficient banking and business development, which is beneficial for both banks and their clients. Future research in this area and the increased application of IB services should provide benefits for all parties involved. However, there are some limitations to the research, related to the sample. Since some of the acquaintances were surveyed, due to the direct distribution of the printed questionnaire to people who do not use the Internet, the sample is not entirely unbiased. For further research, it is recommended to test expanded versions of TAM with more explanatory variables in order to explore additional impacts on the acceptance of IB among users, such as socio-demographic characteristics, marketing efforts, training, or user involvement in design.

\section{References}

[1] AL-Majali, M. and Mat, N. K. N. (2011). Modeling the antecedents of internet banking service adoption (IBSA) in Jordan: A Structural Equation Modeling (SEM) approach. Journal of Internet Banking and Commerce, 16(1), 1-15. http://www.icommercecentral.com/archive/ jibc-volume-16-issue-1-year-2011.html

[2] Awang, Z. (2012). A Handbook on SEM: Structural equation modeling using AMOS graphics, Kelantan: University Technology MARA Press.

[3] Chavan, J. (2013). Internet banking - benefits and challenges in an emerging economy. International Journal of Research in Business Management, 1(1), 19-26.

[4] Chong, A. Y., Ooi, K., Lin, B. and Tan, B. (2010). Online banking adoption: an empirical analysis. International Journal of Bank Marketing, 28(4), 267-287. doi: 10.1108/02652321011054963

[5] Chuttur, M. (2009). Overview of the Technology Acceptance Model: Origins, Developments and Future Directions. Working Papers on Information Systems. Sprouts, 9.

[6] Croatian Bureau of Statistics (2017). Census of Population, Households and Dwellings 2011. https://www.dzs.hr [Accessed 20/09/2016].

[7] Davis, F. (1985). A technology acceptance model for empirically testing new end-user information systems: theory and results. Doctoral Thesis. Cambridg: MIT Sloan School of Management.

[8] Davis, F., Bagozzi, R. and Warshaw, P. (1989). User acceptance of computer technology: a comparison of two theoretical models. Management Science, 35(8), 982-1003. doi: 10.1287/mnsc.35.8.982

[9] Eurostat (2018). Individuals using the internet for internet banking. http://ec.europa.eu/ eurostat [Accessed 07/07/2018].

[10] Gounaris, S. and Koritos, C. (2008). Investigating the drivers of internet banking adoption Decision: A comparison of three alternative frameworks. International Journal of Bank Marketing, 26(5), 282-304. doi: 10.1108/02652320810894370

[11] Hair, J. F., Black, W. C., Babin, B. J. and Anderson, R. E. (2010). Multivariate Data Analysis. New York: Pearson Prentice Hall.

[12] Hanafizadeh, P., Keating, B. W. and Khedmatgozar, H. R. (2014). A systematic review of Internet banking adoption. Telematics and Informatics, 31(3), 492-510. doi: 10.1016/j.tele.2013.04.003

[13] Harris, L. and Spence, L. J. (2002). The ethics of Ebanking. Journal of Electronic Commerce Research, 3(2), 59-66.

[14] Hooper, D., Coughlan, J. and Mullen, M. R. (2008). Structural Equation Modelling: Guidelines for Determining Model Fit. The Electronic Journal of Business Research Methods, 6(1), 53-60. http: //www.ejbrm.com/issue/download.html?idArticle=183

[15] Ibok, N. and Ikoh, I. M. (2013). Determinants of Customers Satisfaction with Internet banking Services. British Journal of Arts and Social Sciences, 14(2), 178-186. 
[16] Kline, R. B. (2011). Principles and Practice of Structural Equation Modeling. New York: The Guilford Press.

[17] Kundid, D. (2017). Factors of acceptance of Internet banking among the population in the City of Split. Master Thesis. University of Split: Faculty of Economics, Business and Tourism.

[18] Liébana-Cabanillas, F., Marinković and V., Kalinić, Z. (2017). A SEM-neural network approach for predicting antecedents of m-commerce acceptance. International Journal of Information Management, 37(2), 14-24. doi: 10.1016/j.ijinfomgt.2016.10.008

[19] Makarević, N. (2016). Perceptions towards IT Security in Online Banking: Croatian Clients vs. Clients of Bosnia and Herzegovina. Journal of Finance and Banking Studies , 5(1), 1-15. doi: 10.20525/ijfbs.v5i1.51

[20] Montazemi, A. R. and Qahri-Saremi, H. (2015). Factors affecting adoption of online banking: A meta-analytic structural equation modeling study. Information and Management, 52(2), 210-226. doi: 10.1016/j.im.2014.11.002

[21] Muzividzi, D., Mbizi, R. and Mukwazhe, C. (2013). An analysis of factors that influence Internet banking adoption among intellectuals: Case of Chinhoy University of Technology. Interdisciplinary Journal of Contemporary Research in Business, 4(11), 350-360.

[22] Ozdemir, S. and Trott, P. (2009). Exploring the adoption of a service innovation: A study of Internet banking adopters and non-adopters. Journal of Financial Services Marketing, 13(4), 284299. doi: $10.1057 /$ fsm.2008.25

[23] Patsiotis, A. G., Hughes, T. and Webber, D. J. (2012). Adopters and non-adopters of internet banking: a segmentation study. International Journal of Bank Marketing, 30(1), 20-42. doi: 10.1108/02652321211195686

[24] Pikkarainen, T., Pikkarainen, K., Karjaluoto, H. and Pahnila, S. (2004). Consumer acceptance of online banking: an extension of the technology acceptance model. Internet Research, 14(3), 224-235. doi: 10.1108/10662240410542652

[25] Polasik, M. and Wisniewski, T. P. (2009). Empirical analysis of internet banking adoption in Poland. International Journal of Bank Marketing, 27(1), 32-52. doi: 10.1108/02652320910928227

[26] Sadeghi, T. and Farokhian, S. (2011). Services quality model for online banking services by behavioral adoption theories and comparative study. African Journal of Business Management, 5(11), 4490-4499.

[27] Safeena, R., Date, H., Hundewale, N. and Kammani, A. (2013). Combination of TAM and TPB in Internet banking Adoption. International Journal of Computer Theory and Engineering, 5(1), 146-150. doi: 10.7763/ijcte.2013.v5.665

[28] Schepers, J. and Wetzels, M. (2007). A meta-analysis of the technology acceptance model: Investigating subjective norm and moderation effects. Information and Management, 44(1), 90-103. doi: 10.1016/j.im.2006.10.007

[29] Schreiber, J. B., Nora, A., Stage, F. K., Barlow, E. A. and King, J. (2006). Reporting Structural Equation Modeling and Confirmatory Factor Analysis Results: A Review. The Journal of Educational Research, 99(6), 323-337. doi: 10.3200/JOER.99.6.323-338

[30] Sharma, S. K. and Govindaluri, S. M. (2014). Internet banking adoption in India: Structural equation modeling approach. Journal of Indian Business Research, 6(2), 155-169. doi: 10.1108/jibr02-2013-0013

[31] Tarhini, A., El-Masri, M., Ali, M. and Serrano, A. (2016). Extending the UTAUT model to understand the customers' acceptance and use of internet banking in Lebanon: A structural equation modeling approach. Information Technology and People, 29(4), 830-849. doi: 10.1108/itp-02-20140034

[32] Tavakol, M. and Dennick, R. (2011). Making sense of Cronbach's alpha. International Journal of Medical Education, 2, 53-55. doi: 10.5116/ijme.4dfb.8dfd

[33] Teddlie, C. and Yu, F. (2007). Mixed Methods Sampling: A Typology With Examples. Journal of Mixed Methods Research, 1(77), 77-100. doi: 10.1177/1558689806292430

[34] Tokić, I. (2014). Usage of the Internet Banking among Legal Entities in the Republic of Croatia. Master Thesis. University of Split: Faculty of Economics, Business and Tourism.

[35] Venkatesh, V. and Davis, F. D. (1996). A model of the antecedents of perceived ease of use: development and test. Decision Sciences, 27(3), 451-481. doi: 10.1111/j.1540-5915.1996.tb00860.x

[36] Yiu, C. S., Grant, K. and Edgar, D. (2007). Factors affecting the adoption of Internet Banking in 
Hong Kong-implications for the banking sector. International Journal of Information Management, 27(5), 336-351. doi: 10.1016/j.ijinfomgt.2007.03.002

[37] Yoon, H. S. and Barker Steege, L. M. (2013). Development of a quantitative model of the impact of customers' personality and perceptions on Internet banking use. Computers in Human Behavior, 29(3), 1133-1141. doi: 10.1016/j.chb.2012.10.005

[38] Yousafzai, S. and Yani-de-Soriano, M. (2012). Understanding customer-specific factors underpinning internet banking adoption. International Journal of Bank Marketing, 30(1), 60-81. doi: $10.1108 / 02652321211195703$ 